University of Nebraska - Lincoln

DigitalCommons@University of Nebraska - Lincoln

U.S. Environmental Protection Agency Papers

U.S. Environmental Protection Agency

2010

EFFECTS FROM FILTRATION, CAPPING AGENTS, AND

PRESENCE/ABSENCE OF FOOD ON THE TOXICITY OF SILVER

NANOPARTICLES TO DAPHNIA MAGNA

\author{
H. Joel Allen \\ U.S. Environmental Protection Agency \\ Christopher A. Impellitteri \\ U.S. Environmental Protection Agency, impellitteri.christopher@epa.gov \\ Dana A. Macke \\ U.S. Environmental Protection Agency \\ J. Lee Heckman \\ Shaw Environmental and Infrastructure \\ Helen C. Poynton \\ U.S. Environmental Protection Agency \\ See next page for additional authors \\ Follow this and additional works at: https://digitalcommons.unl.edu/usepapapers \\ Part of the Civil and Environmental Engineering Commons
}

Allen, H. Joel; Impellitteri, Christopher A.; Macke, Dana A.; Heckman, J. Lee; Poynton, Helen C.; Lazorchak, James M.; Govindaswamy, Shekar; Roose, Deborah L.; and Nadagouda, Mallikarjuna N., "EFFECTS FROM FILTRATION, CAPPING AGENTS, AND PRESENCE/ABSENCE OF FOOD ON THE TOXICITY OF SILVER NANOPARTICLES TO DAPHNIA MAGNA" (2010). U.S. Environmental Protection Agency Papers. 78. https://digitalcommons.unl.edu/usepapapers/78

This Article is brought to you for free and open access by the U.S. Environmental Protection Agency at DigitalCommons@University of Nebraska - Lincoln. It has been accepted for inclusion in U.S. Environmental Protection Agency Papers by an authorized administrator of DigitalCommons@University of Nebraska - Lincoln. 


\section{Authors}

H. Joel Allen, Christopher A. Impellitteri, Dana A. Macke, J. Lee Heckman, Helen C. Poynton, James M. Lazorchak, Shekar Govindaswamy, Deborah L. Roose, and Mallikarjuna N. Nadagouda 


\title{
EFFECTS FROM FILTRATION, CAPPING AGENTS, AND PRESENCE/ABSENCE OF FOOD ON THE TOXICITY OF SILVER NANOPARTICLES TO DAPHNIA MAGNA
}

\author{
H. Joel Allen, $\dagger$ Christopher A. Impellitteri, ${ }^{*} \dagger$ Dana A. Macke, $\dagger$ J. Lee Heckman, $\ddagger$ Helen C. Poynton, $\dagger$ \\ James M. Lazorchak, $†$ Shekar Govindaswamy, $§$ Deborah L. Roose, $†$ and Mallikarjuna N. Nadagouda $\|$ \\ $\dagger$ U.S. Environmental Protection Agency, Office of Research and Development, Cincinnati, Ohio \\ $\ddagger$ Shaw Environmental and Infrastructure, \\ $\S$ Lakeshore Engineering Services, U.S. EPA Test \& Evaluation Facility, Cincinnati, Ohio \\ \|Pegasus Technical Services, 46 East Hollister Street, Cincinnati, Ohio, USA
}

(Submitted 13 October 2009; Returned for Revision 15 December 2009; Accepted 20 June 2010)

\begin{abstract}
Relatively little is known about the behavior and toxicity of nanoparticles in the environment. Objectives of work presented here include establishing the toxicity of a variety of silver nanoparticles (AgNPs) to Daphnia magna neonates, assessing the applicability of a commonly used bioassay for testing AgNPs, and determining the advantages and disadvantages of multiple characterization techniques for AgNPs in simple aquatic systems. Daphnia magna were exposed to a silver nitrate solution and AgNPs suspensions including commercially available AgNPs (uncoated and coated), and laboratory-synthesized AgNPs (coated with coffee or citrate). The nanoparticle suspensions were analyzed for silver concentration (microwave acid digestions), size (dynamic light scattering and electron microscopy), shape (electron microscopy), surface charge (zeta potentiometer), and chemical speciation (X-ray absorption spectroscopy, X-ray diffraction). Toxicities of filtered $(100 \mathrm{~nm})$ versus unfiltered suspensions were compared. Additionally, effects from addition of food were examined. Stock suspensions were prepared by adding AgNPs to moderately hard reconstituted water, which were then diluted and used straight or after filtration with 100-nm filters. All nanoparticle exposure suspensions, at every time interval, were digested via microwave digester and analyzed by inductively coupled argon plasma-optical emission spectroscopy or graphite furnaceatomic absorption spectroscopy. Dose-response curves were generated and median lethal concentration (LC50) values calculated. The $\mathrm{LC} 50$ values for the unfiltered particles were (in $\mu \mathrm{g} / \mathrm{L}$ ): $1.1 \pm 0.1-\mathrm{AgNO}_{3} ; 1.0 \pm 0.1$-coffee coated; $1.1 \pm 0.2$-citrate coated; $16.7 \pm 2.4$ Sigma Aldrich Ag-nanoparticles (SA) uncoated; 31.5 \pm 8.1 SA coated. LC50 values for the filtered particles were (in $\mu \mathrm{g} / \mathrm{L}$ ): $0.7 \pm 0.1-$ $\mathrm{AgNO}_{3} ; 1.4 \pm 0.1$-SA uncoated; $4.4 \pm 1.4-\mathrm{SA}$ coated. The LC50 resulting from the addition of food was $176.4 \pm 25.5$-SA coated. Recommendations presented in this study include AgNP handling methods, effects from sample preparation, and advantages/ disadvantages of different nanoparticle characterization techniques. Environ. Toxicol. Chem. 2010;29:2742-2750. (C) 2010 SETAC
\end{abstract}

Keywords-Silver Nanoparticles Daphnia magna Aquatic toxicity

Toxicity of nanomaterials $(<100 \mathrm{~nm})$ is a relatively new area of ecotoxicological research. Production and application of these materials has increased rapidly; however; their environmental fate and effects are poorly understood. Apparent sizedependent properties such as malleability, optical and electrical properties, and toxicity are desired characteristics in many engineered applications but also may play an important role in their ultimate environmental effects. Estimating current and future relevant environmental concentrations is difficult. However, basic toxicological information can and should be generated. Previous research has investigated the toxicity of nanomaterials in the aquatic environment, including carbon fullerenes [1-3], carbon nanotubes [4-6], and inorganic nanomaterials such as $\mathrm{TiO}_{2}, \mathrm{SiO}_{2}$, and $\mathrm{ZnO}$ [7-9]. Establishing testing and characterization methods specific to nanoparticles and determining the utility of classic aquatic toxicity tests in assessing and managing risks from releases of nanoparticles in the environment are crucial.

The number of manufacturer-identified consumer products containing nano-sized materials roughly doubled between 2006 and 2007 [10] and continues to increase. The main use of silver

All Supplemental Data may be found in the online version of this article.

* To whom correspondence may be addressed

(impellitteri.christopher@epa.gov).

Published online 23 August 2010 in Wiley Online Library (wileyonlinelibrary.com). nanoparticles (AgNPs) is in preventing microbial growth $[11,12]$. This anti-microbial characteristic also means that $\mathrm{Ag}$, especially in ionic form, can be quite toxic to aquatic organisms [13]. Other cited potential uses for AgNPs are in polymers/composites [14,15], textiles [16], and solar energy materials [17]. Silver nanoparticles used as antimicrobial agents (e.g., fabrics containing AgNPs) and impregnated polymers could potentially enter wastewater treatment and aquatic systems.

Past studies show that Ag ions disrupt sodium influx by blocking the functions of $\mathrm{Na}^{+}, \mathrm{K}^{+}$-ATPase, resulting in ionoregulatory disturbance [18]. This agrees with mechanisms observed in fish [19]. Mechanisms of toxicity of AgNPs are less clear. Size dependent activity has been observed in viral inactivation [20]. It has also been suggested that toxicity stems from the production of Ag ions from the oxidation of AgNPs [21], which could cause effects similar to those observed in Ag ion toxicity. The generation of $\mathrm{Ag}$ ion from $\mathrm{AgNPs}$ was also attributed with causing toxicity to freshwater algae [22].

In very simple systems, generation of Ag ions may be the highest risk factor from AgNPs to aquatic organisms. However, it has been well documented that Ag ions react very quickly with common environmental ligands such as sulfide and chloride [23]. These reactions can lead to a decrease in toxicity of the AgNPs [24].

The objectives of this study are to establish the toxicity of different forms of AgNPs to Daphnia magna neonates relative to $\mathrm{AgNO}_{3}$; examine the effects of filtration in the $\mathrm{AgNP}$ 
suspension preparation steps on the toxicity assay results; compare and contrast toxicity results in an assay in which food is present versus the assay without food; assess the effects of coating agents on the toxicity of AgNPs; and characterize the AgNPs using a wide variety of methods. This work contributes to initial efforts to establish baseline toxicity of AgNPs to aquatic invertebrates and to the development of standard operating procedures for creating reproducible exposure suspensions and speciation/identification of AgNPs within the timeframe of typical aquatic toxicity tests.

\section{MATERIALS AND METHODS}

\section{Dilution water}

The test medium was synthetic moderately hard reconstituted water (MHRW), prepared using granular activated carbon and ion exchange filtered Cincinnati (OH, USA) tap water polished to ASTM type II specifications by a Barnstead Nanopure Ultrapure (Barnstead Thermolyne) system following the method described by the U.S. Environmental Protection Agency (U.S. EPA) [25]. Table S1 in the Supplemental Data contains typical values for hardness, alkalinity, $\mathrm{pH}$, specific conductivity, DO, total organic carbon (TOC), and dissolved organic carbon (DOC).

\section{Toxicity assay methods}

Toxicity assays were performed using D. magna. Fortyeight-hour static-renewal tests were performed at least in duplicate following methods described by the U.S. EPA [25] at $25^{\circ} \mathrm{C}$, with mortality as the endpoint. Assays and cultures were provided with a 16:8h light:dark photoperiod. Organically coated $(<100 \mathrm{~nm}, 99.5 \%$ purity, cat. no. 576832) and uncoated AgNPs ( $<150 \mathrm{~nm}, 99 \%$ purity, cat. no. 484059$)$ were purchased from Sigma Aldrich. The manufacturer was contacted for information on the nature of the organic coating, but no information could be obtained because the coating was considered proprietary. The AgNPs were also synthesized using $\mathrm{AgNO}_{3}$ [26] in combination with citrate or coffee solutions. A series of bioassays using $\mathrm{AgNO}_{3}$ (Sigma Aldrich) were performed to compare results with established response values in the literature. Fifty percent serial dilutions were used in the assays with high concentrations ranging from 5 to $400 \mu \mathrm{g} / \mathrm{L}$, depending on initial toxicity results. Observed (i.e., analyzed) concentrations were used for data analysis. For the fed 48-h test, $0.5 \mathrm{ml}$ of an algae/grass extract suspension (Pseudokirchneriella subcapitata, STAR collection) were added at test initiation and renewal. Algae were grown in a large scale mass culture modified from U.S. EPA methods [25]. Less than 24-h-old neonates were held with food before exposure. All tests were covered and slowly aerated using granular activated carbon filtered compressed air to keep the nanoparticles suspended. Four replicates were performed for each concentration for each of the Ag species tested.

One set of toxicity assays were performed for each of the Sigma Aldrich Ag-nanoparticles (SA) AgNP types after the AgNP suspensions were filtered (100-nm nylon filter, GE/ Osmonics). Results from these assays were compared with results from exposures to suspensions that were not filtered. For stock suspensions that were filtered, a mass of AgNPs were transferred to acid-washed 1-L volumetrics, suspended in MHRW, and sonicated for $15 \mathrm{~min}$. The suspensions were then agitated by inverting (three times) and filtered through 100-nm nylon syringe filters. This process is commonly used to remove aggregates of nanoparticles. For stock suspensions without sonication or filtration, the AgNPs were added to MHRW and agitated. After stock suspension preparation, samples of AgNPs of all types were transferred to microwave digestion vessels (MARS, CEM Corporation) for digestion in triplicate, by U.S. EPA method 3015A (without the addition of $\mathrm{HCl}$ ) [27] and analyzed by inductively coupled argon plasma-optical emission spectrometry (ICP-OES, Model Optima 2100, Perkin Elmer). If the relative standard deviation for a set of stock suspension replicates was less than $20 \%$, the replicate values were averaged and recorded as the stock suspension concentration. Fresh stock solutions were prepared for each bioassay and stored in the dark for no longer than one week. Dissolution of silver nanoparticles was not directly evaluated, but zeta potential measurements of the suspensions showed good stability of citrate- and coffee-capped particles over a three-month period (data not shown). Different stirring rates (50, 100, and $200 \mathrm{rpm}$ on magnetic stir plate) and agitation methods (e.g., gentle inversion vs vigorous shaking) were used to determine the most effective method for generating reproducible transfers of the stock suspension either to microwave digestion vessels or vessels for the working suspensions. To monitor the experiments as thoroughly as possible, every suspension used in a particular assay was digested and analyzed at $\mathrm{T}=0,24$, and $48 \mathrm{~h}$; at every time period when the suspension was replaced. The entire volume of the exposure cup $(25 \mathrm{ml})$ was directly transferred to a Teflon ${ }^{\circledR}$ microwave digestion vessel. Each suspension was quantitatively transferred with two separate aliquots of trace metal grade $\mathrm{HNO}_{3}$. The total volume of $\mathrm{HNO}_{3}$ added was $10 \mathrm{ml}$. In preliminary experiments, recoveries and reproducibility (four exposure replicates per exposure concentration) were greatly improved with the $\mathrm{HNO}_{3}$ rinses. After digestion, the suspensions were analyzed either by inductively coupled argon plasma-optical emission spectrometer (instrument detection limit $=10 \mu \mathrm{g} / \mathrm{L}$ ) or by graphite furnace atomic absorption (GFAA-Model AA240Z, Varian, instrument detection limit $=0.5 \mu \mathrm{g} / \mathrm{L})$. Critical factors influencing suspension concentration reproducibility were the method of agitation and type and size of the stock transfer pipette.

\section{Bioassay statistical analysis}

Data generated from the assays were pooled by toxicant, filtration, and feeding. Dose-response curves (DRC) were generated using the DRC package [28] in the $\mathrm{R}$ statistical package [29]. Curves were generated using a two-parameter logistic model. Curve fit was visually assessed. The chi-squared test for heterogeneity was not used to assess lack of fit, because large values of the goodness-of-fit test can result from data that include contributions from concentrations with small expected values [30,31]. Variability was expressed using a 95\% confidence interval. The EC50 values were compared using the likelihood-ratio test at the $\alpha=0.05$ level.

\section{$X$-ray absorption spectroscopy}

One-gram samples of coated and uncoated AgNPs were equilibrated for $48 \mathrm{~h}$ in MHRW in the presence and absence of chloride (1.0 M sodium salt). A silver salt, $\mathrm{AgSO}_{4}$, was also equilibrated for $48 \mathrm{~h}$ with $\mathrm{MHRW}$ and $1.0 \mathrm{M} \mathrm{NaCl}$. Silver reference materials included $\mathrm{AgCl}, \mathrm{AgSO}_{4}, \mathrm{Ag}$-foil (elemental $\mathrm{Ag}$ ), and coated and uncoated AgNPs. The samples and reference materials were mounted between two sections of Kapton tape. Silver $(\mathrm{K}$-edge $=25,514 \mathrm{eV}$ ) X-ray absorption near edge structure data were collected at beamline 10-ID (Materials Research Collaborative Access Team) at the Advanced Photon Source at Argonne National Laboratory, Argonne, IL, USA. 
The electron storage ring operated at $7 \mathrm{GeV}$. A liquid nitrogencooled double crystal $\mathrm{Si}(111)$ monochromator was used to select incident photon energies, and a platinum-coated glass mirror was used for harmonic rejection.

At least three scans were collected for each sample. The $\mathrm{X}$-ray absorption near edge structure spectra were collected in fluorescence mode using ionization chambers for the incident, transmitted, fluorescence, and reference channels. The collected scans for a particular sample were aligned using a reference Ag foil and averaged. The averaged data were then normalized, and the background was removed by spline fitting using the X-ray absorption spectroscopy data processing program Athena [32].

\section{$X$-ray diffraction}

X-ray diffraction (Xpert Pro, PANalytical B.V.) was used to identify crystalline phases of AgNPs using $\mathrm{Cu} \mathrm{K} \alpha$ radiation at $45 \mathrm{kV}$ and $40 \mathrm{~mA}$. Scans ranged from 5 to 90 degrees 2 theta, with 0.02-degree step sizes that were held for $2 \mathrm{~s}$ each. Pattern analysis was performed using the Jade+ software v.7 (MDI), which follows ASTM D934-80 procedures. Sample spectra were compared with reference patterns from the 2002 Powder Diffraction File (2nd release, International Center for Diffraction Data).

\section{Scanning and transmission electron microscopy}

Scanning electron microscopy (SEM, JEOL-6490-LV, JEOL) was performed at the U.S. EPA's National Risk Management Research Laboratory in Cincinnati, OH. The AgNP samples were placed on double-sided carbon tape and mounted on an aluminum sample stub. Images were created for particles in MHRW and D. magna neonates exposed to LC50 concentrations of AgNPs. The organisms were imaged in their entirety after desiccation and placement on the aluminum sample stub. The exteriors of the organisms were imaged to ascertain the presence/absence of sorbed AgNPs to surfaces (i.e., antennae, setae, carapace). Energy dispersive X-rays (EDX, X-act EDS, Oxford Instruments) were used to identify elements present at particular spots in the samples.

Transmission electron microscopy (TEM) was performed at the U.S. EPA's National Risk Management Research Laboratory (particles), the University of Cincinnati (Ohio, USA) (particles), and Purdue University (West Lafayette, Indiana, USA) (D. magna and particles). Particles passing through a 100-nm filter were analyzed by TEM (JEOL-1200EXII, JEOL) at the U.S. EPA's National Risk Management Research Laboratory laboratory. Images were captured using a Gatan digital camera. Samples were placed on a carbon-coated grid, air dried, and collected at an accelerating voltage of $120 \mathrm{kV}$.

Particle suspensions were also analyzed in stock solutions at the beginning of the experiments at the Material Characterization Laboratory at the University of Cincinnati by TEM (CM-20, Phillips). The nanoparticle suspensions were placed on a $\mathrm{Cu}$ grid and air dried, and images were collected at an accelerating voltage of $200 \mathrm{kV}$. The images were collected using a Gatan ORIUS ${ }^{\mathrm{TM}}$ 8-megapixel imaging system. In addition, a confirmatory analysis (for Ag presence) was performed on some of the imaged samples, using an EDX Energy dispersive system (Genesis XMS 2000, EDAX).

Transmission electron microscopy images of exposed $D$. magna were generated at Purdue University. D. magna, exposed at approximate LC50 concentrations, were preserved in $2 \%$ glutaraldehyde at U.S. EPA's National Risk Management Research Laboratory and transported to Purdue University. The organisms were then washed in a 0.1-M cacodylate buffer
( $\mathrm{pH} 7.4[2 \times])$, washed in deionized water, dehydrated with ethanol, and embedded in Spurr's resin. Thin sections (1- to 2- $\mu \mathrm{m}$ cross sections) stained with uranyl acetate and lead citrate were made and analyzed by TEM, using an FEI/Phillips CM-100 transmission electron microscope. Identifying Ag nanoparticles from other darkly staining particles was difficult. Therefore, most images were taken without staining with uranyl acetate and lead citrate. Images of the samples were created at similar distances from the tail $(80-100 \mu \mathrm{m})$. At this point both gill and midgut were visible in the thin sections.

Images of particles were also taken on the Purdue University TEM, using an accelerating voltage of $80 \mathrm{kV}, 50-\mathrm{m}$ objective aperture, and spot 3. Magnifications varied between 3,900 $\times$ and $52,000 \times$. Images were captured on Kodak Electron Image Type S0-163 film.

\section{Dynamic light scattering}

Particle size/hydrodynamic diameter (HDD) was determined by dynamic light scattering (DLS) using a Zetasizer Nanoseries (Malvern Instruments) with a 633-nm laser source and a detection angle of $173^{\circ}$ (detection range, $1 \mathrm{~nm}$ to $10 \mu \mathrm{m}$ ). Measurements were conducted using a $2 \mathrm{ml}$ sample deposited in a disposable polystyrene cuvette. Reported measurements represent the average, by cumulants analysis as described in the International Standard on DLS ISO13321 Part 8 [33], of at least 12 independent measurements. The size distribution was obtained from a nonnegative least squares analysis and based on particle concentration introduced into the instrument. The instrument measures the hydrodynamic diameter, the diameter of a sphere that has the same diffusion coefficient as the particles in solution.

\section{Zeta potential}

Zeta potentials were calculated from micro electrophoresis measurements collected from the Malvern DLS instrument, using a disposable electrophoretic flow through cell with an internal volume of approximately $1 \mathrm{ml}$. Ten milliliters sample was flushed through the flow cell before measurement to avoid contamination from a previous measurement. Based on preliminary data, the voltage applied to the capillary cell was set at $100 \mathrm{mV}$, and a Henry function ( $f[\mathrm{Ka}]$ ) of 1.5 to 1.23 was used to calculate zeta potential. Zeta potential was measured at ambient $\mathrm{pH}$. The reported zeta potential values are the average of 10 micro electrophoresis measurements. The standard deviation for all zeta potential measurements was less than $1.5 \mathrm{mV}$. The SA particles were analyzed in deionized water and MHRW. The coffee-capped particles were measured in MHRW. The citratecapped particles were not suspended in MHRW, because the nanoparticles were at low silver concentrations, and the instrument requires perceptible color/turbidity in colloidal solutions for the measurements.

\section{RESULTS}

\section{Toxicity}

Responses of D. magna to the AgNPs were dependent on dose. The LC50 values of the eight combinations of treatments are found in Table 1. Dose-response curves are presented in Figure 1. Toxicity of the AgNPs (without the addition of food) spanned an order of magnitude. The laboratory-synthesized AgNPs coated with coffee or citrate resulted in dose-responses similar to, but slightly higher than, the $\mathrm{AgNO}_{3}$ solution. For the SA AgNPs, the coated form was less toxic than the uncoated form, and the filtered suspensions (for coated and uncoated) 
Table 1. 48-h median lethal concentration (LC50) values of ionic silver and silver nanoparticle exposures ${ }^{\mathrm{a}}$

\begin{tabular}{lcrrrr}
\hline Ag type & Filtered & Fed & LC50 $\mu \mathrm{g} / \mathrm{L}$ & $95 \% \mathrm{CI}$ & Group \\
\hline $\mathrm{AgNO}_{3}$ & $\mathrm{X}$ & & 0.7 & 0.1 & $\mathrm{~A}$ \\
$\mathrm{AgNO}_{3}$ & & 1.1 & 0.1 & $\mathrm{~B}$ \\
Citrate-coated AgNPs & & 1.1 & 0.2 & $\mathrm{~B}$ \\
Coffee-coated AgNPs & & & 1.0 & 0.1 & $\mathrm{~B}$ \\
SA-coated AgNPs & $\mathrm{X}$ & & 4.4 & 1.4 & $\mathrm{D}$ \\
SA-coated AgNPs & & & 31.5 & 8.1 & $\mathrm{~F}$ \\
SA-coated AgNPs & & $\mathrm{X}$ & 176.4 & 25.5 & $\mathrm{G}$ \\
SA-uncoated AgNPs & $\mathrm{X}$ & & 1.4 & 0.1 & $\mathrm{C}$ \\
SA-uncoated AgNPs & & & 16.7 & 2.4 & $\mathrm{E}$ \\
\hline
\end{tabular}

${ }^{\mathrm{a}} \mathrm{AgNPs}=$ silver nanoparticles; $\mathrm{SA}=$ Sigma Aldrich silver nanoparticles.

were more toxic than their unfiltered counterparts. Addition of food resulted in an increase of TOC from $0.348 \mathrm{mg} / \mathrm{L}$ to $1.651 \mathrm{mg} / \mathrm{L}$ and an order of magnitude decrease in the toxicity of the SA coated (unfiltered) AgNPs.

\section{Silver analyses}

Initial results showed low recoveries of digested AgNPs from the organism exposure cups. The qualitative transfer of the Ag suspensions improved recoveries (Fig. S1). Percent relative standard deviations for the exposure suspensions were generally between 5 and $20 \%$.

These results indicate that not all recovered Ag was available to the organisms, possibly overestimating the actual suspended Ag causing toxicity. Occasionally (1-2 times per assay), an outlier occurred for a particular treatment level. This was attributed to the inclusion of a large aggregate of AgNP for that particular replicate during the dilution/transfer process. This tended to occur more often for the uncoated SA AgNP. The outliers were eliminated from the statistical analysis based on this assumption and concentration values were replaced with the mean of the remaining replicates. All statistical analyses were based on actual analyzed concentrations. Trends common to all of the AgNPs were decreasing nominal concentration deviance with increasing suspension concentration, and increasing precision with increasing nominal (or target) concentrations.

Gentle inversion $(3-4 \times)$ followed by immediate pipetting produced more repeatable transfers of stock suspensions from the $1 \mathrm{~L}$ volumetrics. Constant stirring tends to produce a vortex that forces the nanoparticles to the sides of the vessel. The use of the exact same type of pipette also helped to minimize error from assay to assay.

Filtration experiments through 100-nm filters resulted in most or all of the laboratory-synthesized particles passing through the filter $(94.5 \pm 5.0 \%$ for coffee-capped, $114 \% \pm$ $0.5 \%$ for citrate). However, less than $1 \%$ of the SA particles passed through the 100 -nm filters.

\section{DLS-size results}

Results for size measurements using the DLS are presented in Table 2. The MHRW had little effect on the size measurements compared with those made in the deionized $\mathrm{H}_{2} \mathrm{O}$ matrix. Strong evidence exists for aggregation of particles, especially the SA uncoated, as seen by the size distributions of the particles. The size results from the DLS do not agree, in many instances, with TEM results, because approximately $75 \mathrm{ppb}$ was used to generate TEM data, whereas more than 20,000 ppb Ag was required to generate size data using the zeta sizer. The nanoparticles have a tendency to aggregate at higher concentrations (Sigma Aldrich Material Safety Data Sheet). Another experimental artifact from the DLS measurements was seen when the coffee-capped particle size distribution changed with dilution rate. At 1:100 dilution (maximum permissible dilution, in this case, for analysis), the larger particles were $40 \%$ smaller in size $(774 \mathrm{~nm}$ vs $1,285 \mathrm{~nm})$. High suspension concentrations are necessary for DLS measurements. The AgNPs tend to aggregate at higher concentrations. Thus, an experimental bias exists toward the formation (and measurement) of larger particles (really aggregates) with the DLS instrument.

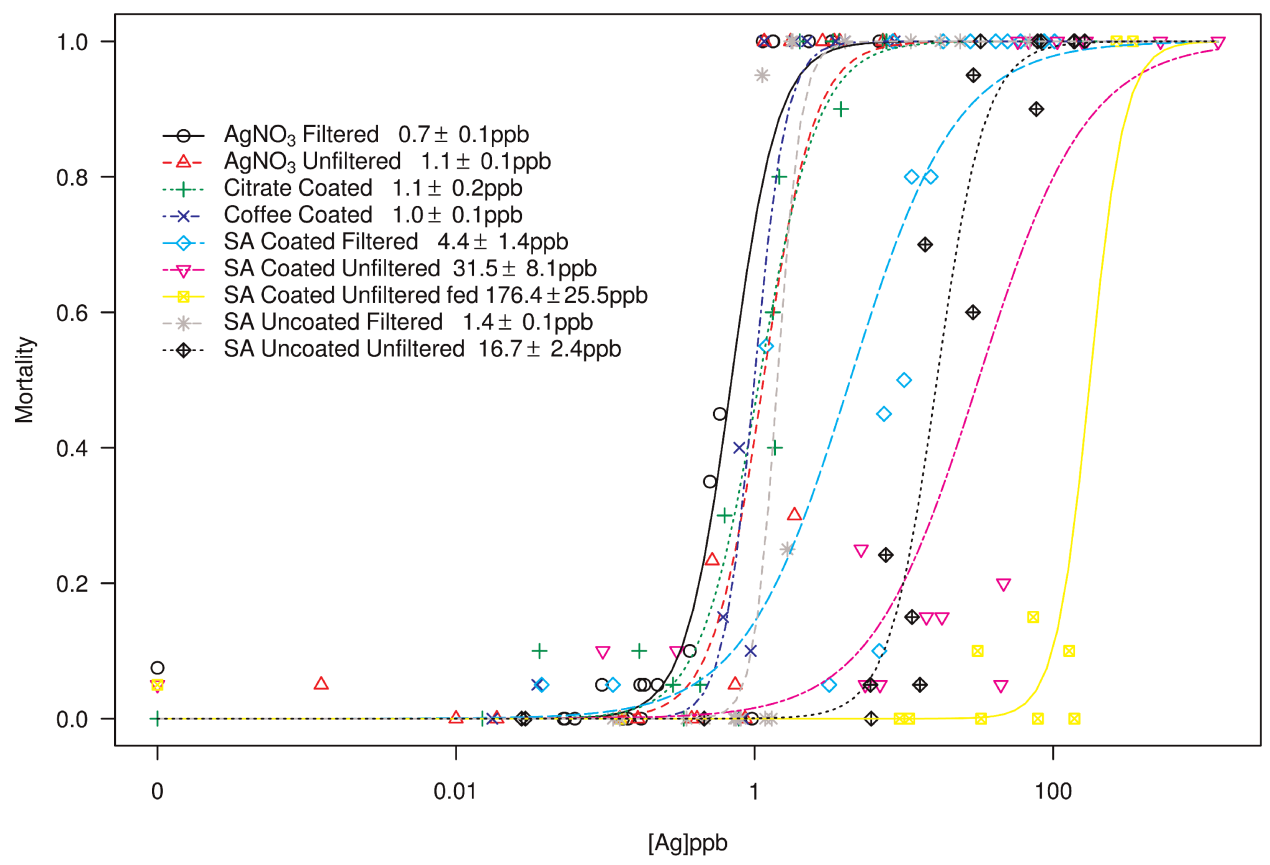

Fig. 1. Dose-response curve of D. magna to silver nanoparticles (AgNPs). The assay duration was $48 \mathrm{~h}$ with renewal. SA $=$ Sigma Aldrich silver nanoparticles. 
Table 2. Dynamic light scattering size measurements in deionized water (DI) and moderately hard reconstituted water (MHRW)

\begin{tabular}{|c|c|c|c|c|c|}
\hline \multirow[b]{2}{*}{ Particle type } & \multirow[b]{2}{*}{$\begin{array}{c}\text { Approx Ag } \\
\text { concentration (ppb) }\end{array}$} & \multirow[b]{2}{*}{ Matrix } & \multicolumn{3}{|c|}{ Size distribution of particles } \\
\hline & & & Size $1, \%$ & Size $2, \%$ & Size $3, \%$ \\
\hline SA uncoated* & $>100,000$ & DI water & $839.5 \mathrm{~nm}, 73.4 \%$ & $5,021 \mathrm{~nm}, 26.6 \%$ & \\
\hline SA uncoated* & $>100,000$ & MHRW & $681.4 \mathrm{~nm}, 81.4 \%$ & $5,412 \mathrm{~nm}, 18.6 \%$ & \\
\hline SA coated* & $>100,000$ & DI water & $14.85 \mathrm{~nm}, 73.3 \%$ & $58.27 \mathrm{~nm}, 24.4 \%$ & $368.9 \mathrm{~nm}, 4.3 \%$ \\
\hline SA coated ${ }^{*}$ & $>100,000$ & MHRW & $39.39 \mathrm{~nm}, 73.5 \%$ & $249.8 \mathrm{~nm}, 26.5 \%$ & \\
\hline Coffee capped $1: 10$ dilution & 215,800 & DI water & $106.3 \mathrm{~nm}, 22.4 \%$ & $1,285 \mathrm{~nm}, 77.6 \%$ & \\
\hline Coffee capped $1: 100$ dilution & 21,580 & MHRW & $101.5 \mathrm{~nm}, 30.5 \%$ & $773.6 \mathrm{~nm}, 69.5 \%$ & \\
\hline Citrate capped & 70,000 & Nanopure & $5.94 \mathrm{~nm}, 98 \%$ & $39.75 \mathrm{~nm}, 2 \%$ & \\
\hline
\end{tabular}

${ }^{*}$ Sonicated prior to analysis. SA $=$ Sigma Aldrich silver nanoparticles.

\section{DLS-zeta potential measurements}

The results for the zeta potential measurements are shown in Table 3. The MHRW significantly decreased electrokinetic potential and suspension stability of the SA particles. These results suggest that the particles will have a greater tendency to aggregate in MHRW compared with suspensions in deionized water.

\section{X-ray absorption spectroscopy}

$\mathrm{X}$-ray absorption spectroscopy results (in the near-edge range) are presented in Figure 2. The results show no evidence for the formation of $\mathrm{AgCl}$ in the $\mathrm{AgNP}$ sample equilibrated with $1 \mathrm{M} \mathrm{NaCl}$ (nor for AgNPs equilibrated with MHRW; data not shown). No evidence exists for the formation of $\mathrm{AgCl}$ when a weakly associated $\mathrm{Ag}$ salt $\left(\mathrm{AgSO}_{4}\right)$ is equilibrated with MHRW for $48 \mathrm{~h}$. However, strong evidence suggests the conversion of $\mathrm{AgSO}_{4}$ to $\mathrm{AgCl}$ in the $1 \mathrm{M} \mathrm{NaCl}$ solution. These results suggest that the AgNPs remain predominantly elemental Ag over the course of the bioassays.

\section{$X$-ray diffraction}

All of the AgNPs in the current study were identified as elemental silver by X-ray diffraction. The coffee-capped nanoparticles had an additional peak at approximately $17^{\circ} 2 \theta$. All $\mathrm{X}$-ray diffraction spectra are presented in the supplemental information (Figs. S2a-c).

\section{Microscopy particles}

Transmission electron microscopy images for the SA Ag, citrate-coated, and coffee-coated particles are presented in the Supplemental Data (Figs. S3-S6). The coated particles tended to aggregate more than the uncoated particles. The aggregates appear in a gel-like amorphous matrix, which is probably associated with the capping agent. The SA uncoated particles seemed to have higher variations in particle size. Comparisons

Table 3. Dynamic light scattering zeta potential measurements of AgNPs in deionized water (DI) and moderately hard reconstituted water (MHRW)

\begin{tabular}{lccccc}
\hline Particle type & Matrix & $\mathrm{pH}$ & $\begin{array}{c}\text { Zeta } \\
\text { potential, } \\
\mathrm{mV}\end{array}$ & $\begin{array}{c}\text { Zeta } \\
\text { deviation, } \\
\mathrm{mV}\end{array}$ & $\begin{array}{c}\text { Expected } \\
\text { stability }\end{array}$ \\
\hline SA coated & DI & $6.8-7.0$ & -38.0 & 6.31 & Moderate \\
SA coated & MHRW & $7.8-8.0$ & -18.3 & 6.11 & Incipient \\
SA uncoated & DI & $6.8-7.0$ & -41.2 & 5.59 & Good \\
SA uncoated & MHRW & $7.8-8.0$ & -20.4 & 5.65 & Incipient \\
Coffee capped & MHRW & $7.8-8.0$ & -9.3 & 4.15 & Poor \\
Citrate capped & Nanopure & $6.8-8.0$ & -39.7 & 19.5 & Moderate \\
\hline
\end{tabular}

among the filtered $(100 \mathrm{~nm})$ versus the unfiltered nanoparticle suspensions show that particles are present in all of the filtered suspensions (Fig. 3). Although the SA suspensions had a high percentage of particles removed, enough particles passed through the filter that stock suspensions could be made.

\section{Microscopy organisms}

Scanning electron microscope images of representative D. magna samples are presented in the supplemental information (Fig. S6). No evidence was seen of AgNPs on any of the exterior surfaces of the organisms. This was probably because of sample preparation procedures (e.g., washing, fixation, desiccation). Results from EDX analyses on the organism exteriors showed high concentrations of $\mathrm{Ca}$, which was probably attributable to precipitated salts from the MHRW.

Transmission electron microscopy images of D. magna exposed to approximate LC50 concentrations yielded the following qualitative results: SA uncoated: no Ag nanoparticles detected (no images were taken); SA coated: a few silver particles were found along the membrane of the mid-gut; coffee-capped: a few particles were found around the gill and gut; citrate-capped: a few more particles were found around the gills and gut; control: a particle was found at the side of the gill, but no particles were found inside gut tissue (Fig. S7); coffee-capped, $(3 \times$ LC50): a few particles were found in the gill region, and some particles were found in the tissue of the mid-gut; citrate-capped, $(3 \times$ LC50): more AgNPs were found

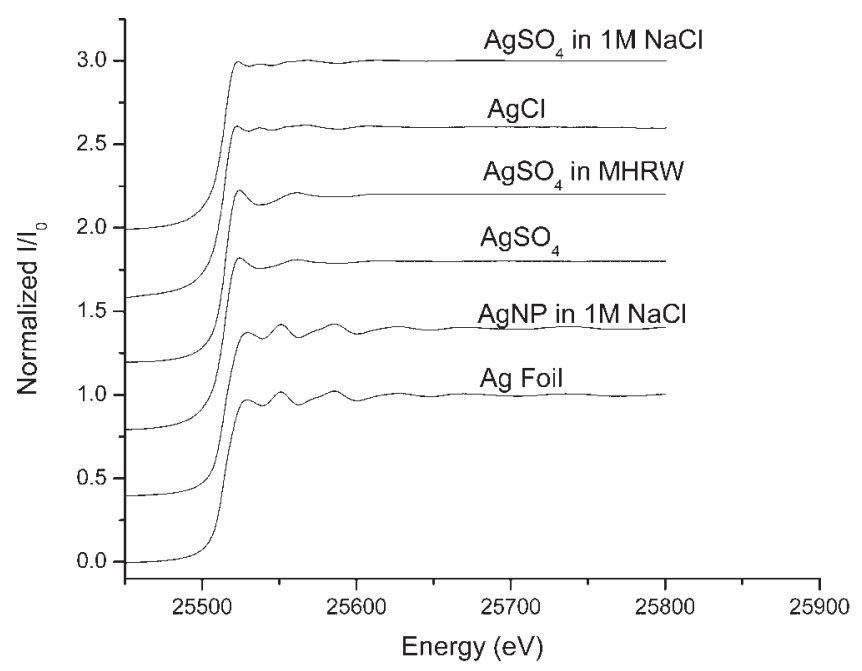

Fig. 2. X-ray absorption spectroscopy spectra for silver compounds and silver nanoparticles equilibrated with $1 \mathrm{M}$ sodium chloride solutions or moderately hard reconstituted water. 

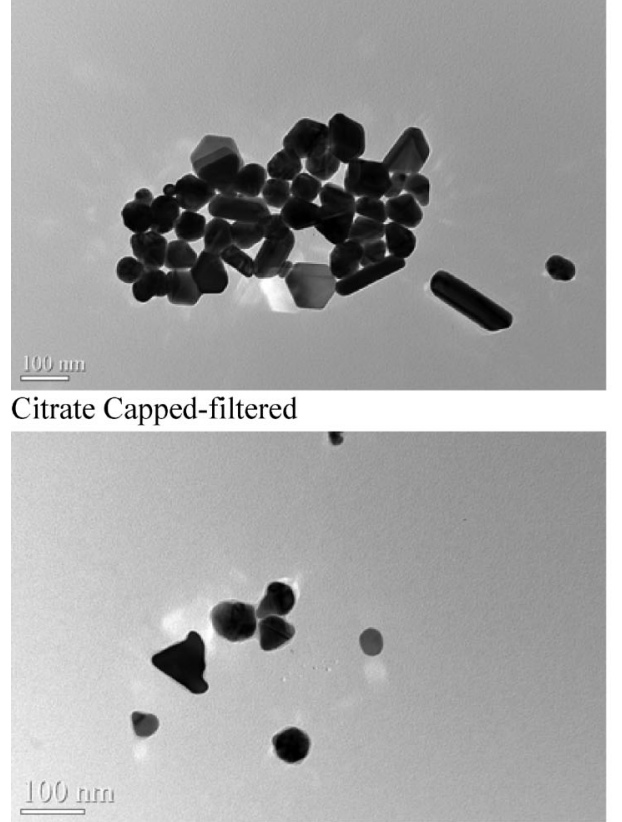

\section{Coffee Capped-filtered}

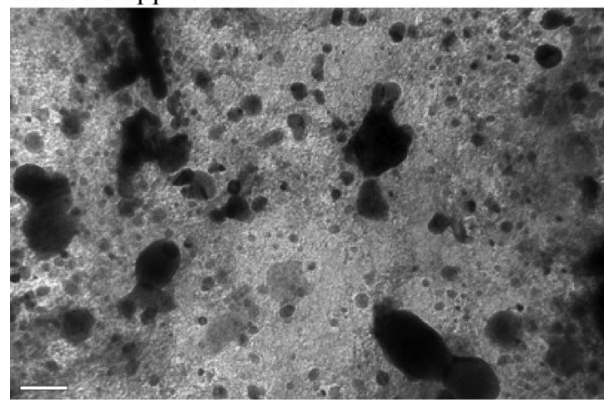

Aldrich coated-filtered

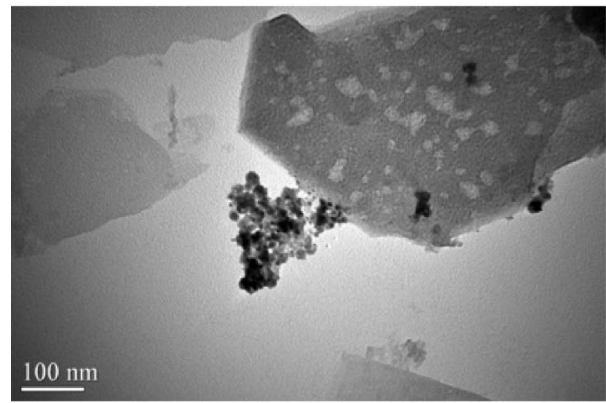

Aldrich uncoated-filtered

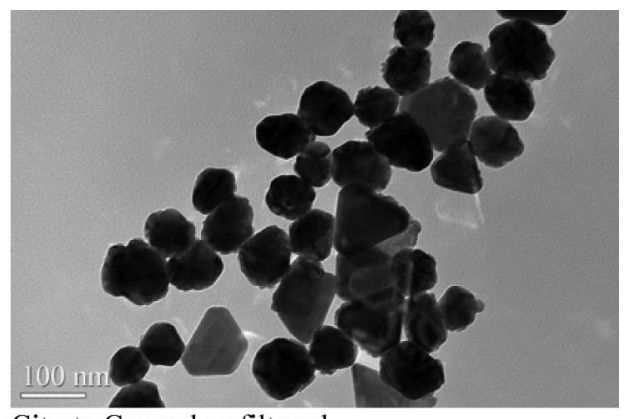

Citrate Capped-unfiltered

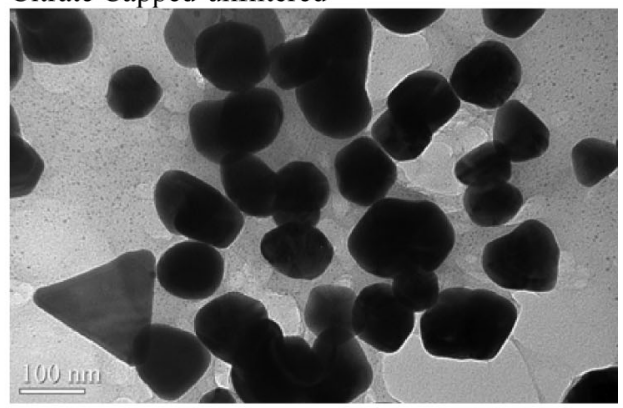

Coffee Capped-unfiltered

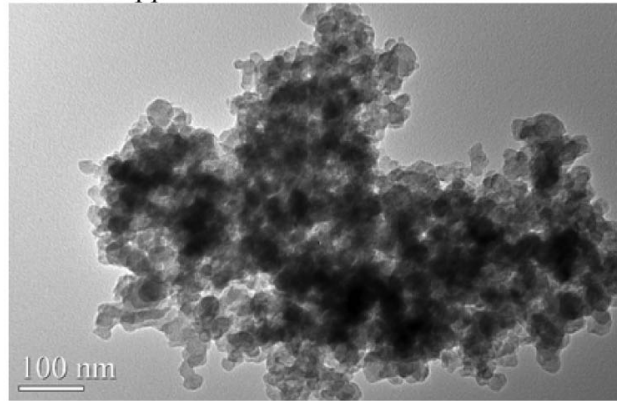

Aldrich coated-unfiltered

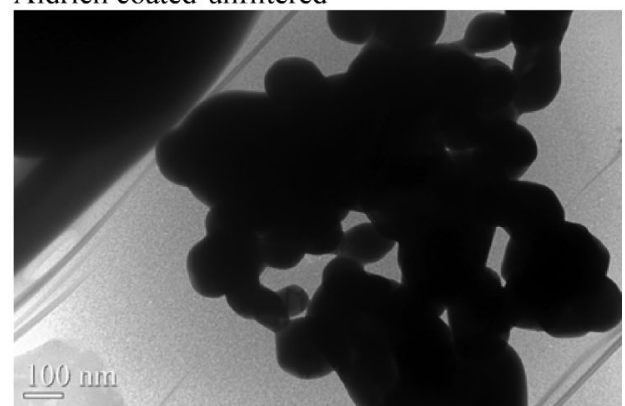

Aldrich uncoated-unfiltered

Fig. 3. Transmission electron microscopy images of filtered $(100 \mathrm{~nm})$ suspensions versus unfiltered suspensions.

in the gill or in the gut in this sample compared with the other AgNP types. Figure 4 shows the full cross section of a $D$. magna exposed to the citrate particles. Figure 5 is an expanded view of the gut. Particles identified as AgNPs are marked by arrows. Figure 6 is a TEM image of the citrate-coated particles at approximately the same scale as Figure 5, taken by the same microscope. The EDX analyses were not performed on the $D$. magna sections.

\section{DISCUSSION}

\section{Sample handling and preparation}

Silver nanoparticles are extremely difficult to work with in aquatic toxicity experiments because of their reactivity and toxicity. The AgNPs may oxidize to $\mathrm{Ag}$ ion and react to form $\mathrm{Ag}_{2} \mathrm{~S}, \mathrm{AgCl}$, or other compounds, depending on the ligands present. Silver nanoparticles have a tendency to sorb onto surfaces as well. The use of vigorous transfer techniques (e.g., triple nitric acid rinses) can enhance accuracy and precision when assessing exposure concentrations. Nominal concentrations for exposures should never be assumed with AgNPs; analyses of all replicates should be performed. This makes classic toxicity assays particularly burdensome with AgNPs. The toxicity of $\mathrm{Ag}$ to D. magna neonates used in this study is such that the lower toxicity values (i.e., LC25) are in many instances at or about the detection limits for standard U.S. EPA digestion methods. Another challenge when working with AgNPs is the repeatability of stock suspensions and dilutions for exposures. Transfer techniques must be repeated very carefully from assay to assay and, to ensure accuracy, all stock suspensions, filtered or unfiltered, must be analyzed before the bioassays. 


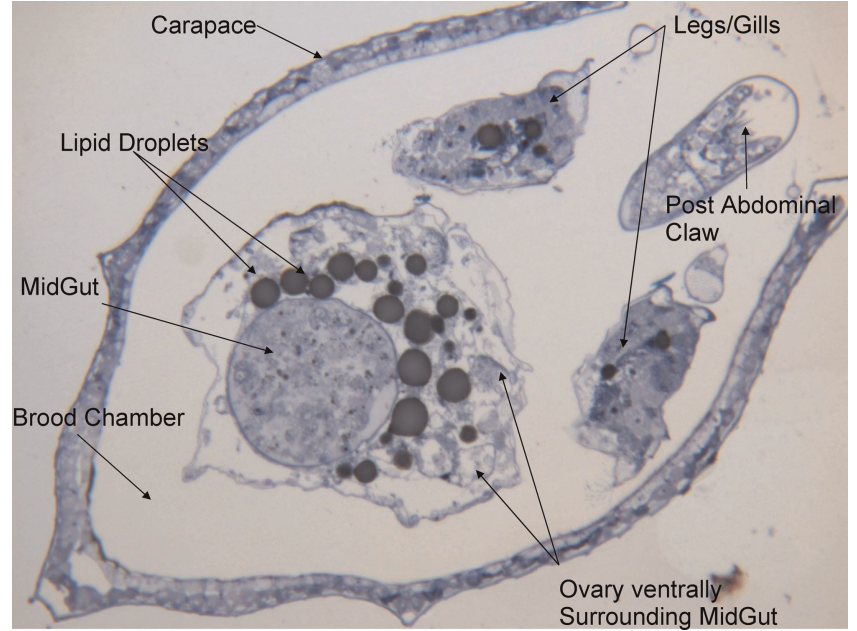

Fig. 4. Cross section of Daphnia magna. [Color figure can be seen in the online version of this article, available at wileyonlinelibrary.com]

For the actual bioassays, methods must be employed to maximize the homogeneity of the exposure suspension. At higher concentrations, accumulation of particles, for some of the particle types, was observed on the bottom of the exposure cups. To maximize homogeneity of the assay medium, stirring during preparation of stock and mixing (e.g., inversion of the suspension three to four times) during dilutions was found to be a reproducible method (relative SD for replicate measurements $<20 \%$ ). Under aeration, no particles were observed settling out. However, aeration can cause problems for the D. magna neonates if they become trapped in air bubbles. This phenomenon caused many of our controls to fail, thus requiring the exposure assay to be repeated.

\section{Nanoparticle characterization}

Assessing, as much as possible, the size and chemical speciation of the AgNPs throughout a particular experiment, with an emphasis on characterization in the media of interest, is imperative. This is especially true because many different types (sizes, shapes, coatings, etc.) of nanoparticles are employed in

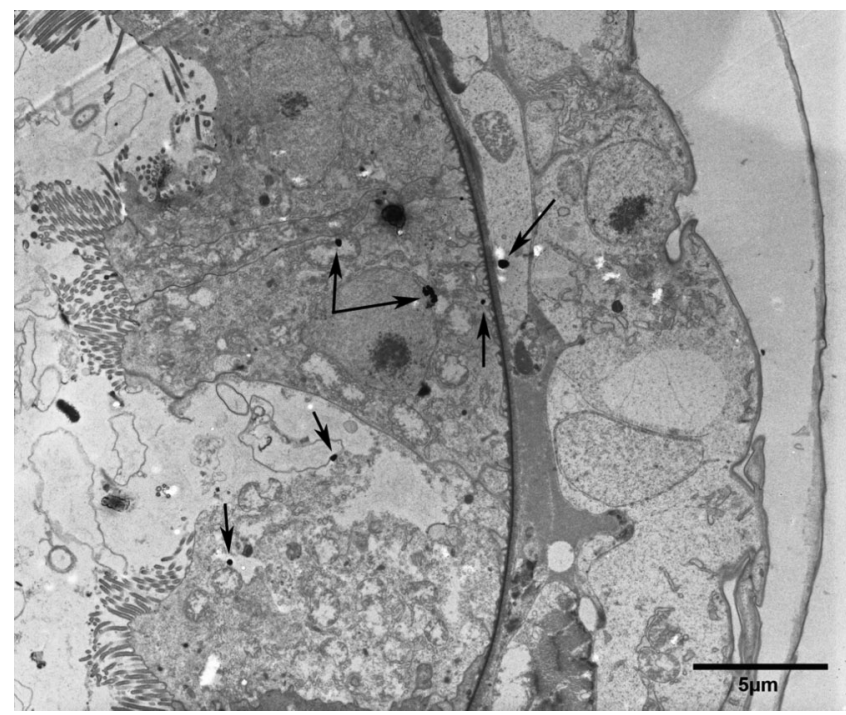

Fig. 5. Expanded view of the mid gut in cross section. Arrows point out features identified as silver nanoparticles (compared with TEM images at similar scale in Fig. 6).

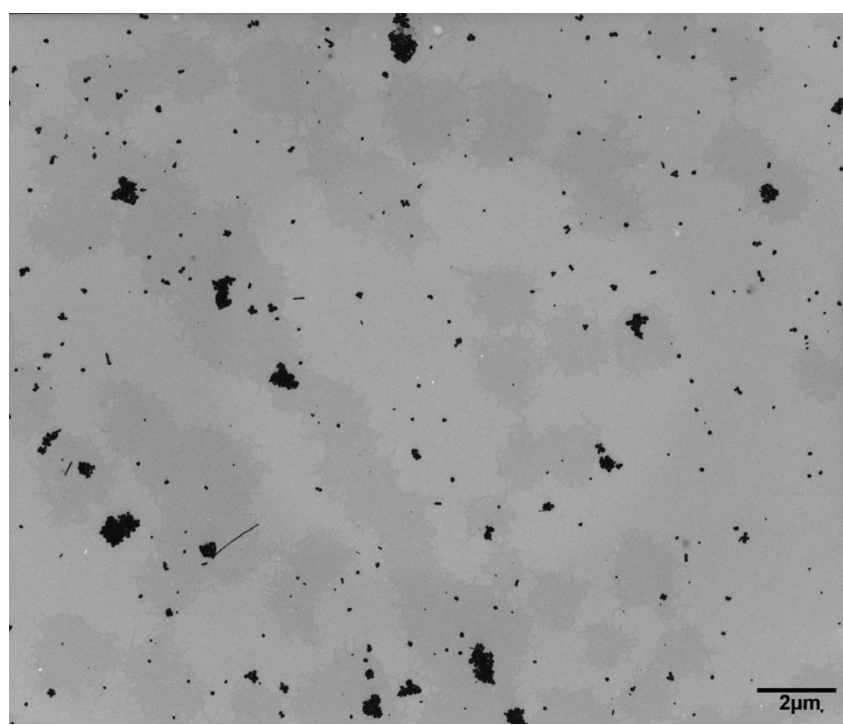

Fig. 6. TEM image of citrate-capped nanoparticles used in exposure from organism in Figure 5.

materials, and the number of different types will surely increase in the future.

If oxidized, AgNPs will react swiftly with many different ligands. This can change their bioavailability or toxicity. The AgNPs may also aggregate, depending on surface charge (which can be a function of the media they are in) and concentration. Researchers should be aware that different measurement methods may yield different results for size. The DLS instrumentation used in this work requires highly concentrated suspensions. The high concentrations can lead to increased aggregation and results that suggest larger particle sizes than are witnessed using electron microscopy.

Preparation of samples for microscopy will probably affect the location of, and perhaps completely remove, particles on the exterior of organisms. Ideally, high-resolution TEM equipped with an EDX could be used to identify particles. However, depending on the localized concentration of AgNPs, EDX may not provide useful data. The concentration of any target analyte for EDX data must be relatively high.

This is also the case for X-ray absorption spectroscopy, which requires concentrations in the hundreds of $\mathrm{ppm}$ for chemical speciation and bonding mechanism data. In the research presented here, no evidence could be found for the oxidation/transformation (to $\mathrm{AgCl}$ ) by the AgNPs in MHRW. More specifically, no evidence was found at the ppm to percent level. Surface sites may exist on individual particles that are oxidized and converted to $\mathrm{AgCl}$, which escape detection by $\mathrm{X}$-ray absorption spectroscopy.

A combination of multiple characterization techniques is best suited for AgNP work to provide as many clues as possible on the nature of the particles themselves. This research is in relatively simple media. Experiments in increasingly complex media will result in more difficulty in characterization of AgNPs.

\section{Toxicity results}

Results indicate that many of the AgNPs used in this study have toxicity characteristics similar to those of ionic silver. The observed acute toxicity was highest for the laboratory-synthesized AgNPs. Toxicity of the SA uncoated particles was slightly higher than the SA coated particles, and, for the SA particles, 
the unfiltered suspensions yielded higher LC50 values. The addition of food decreased toxicity of the SA uncoated particles by an order of magnitude. Toxicity of the laboratorysynthesized particles agrees well with the $\mathrm{AgNO}_{3}$ assay values and also with published data for D. magna silver salt assays. Elnabarawy et al. [34] reported a $48-\mathrm{h}$ LC50 of $1.5 \mu \mathrm{g} / \mathrm{L}$ (alkalinity $=230 \mathrm{mg} / \mathrm{L}$ as $\mathrm{CaCO}_{3}$, hardness $=240 \mathrm{mg} / \mathrm{L}$ as $\mathrm{CaCO}_{3}$ ), Erickson et al. [35] reported $0.58 \mu \mathrm{g} / \mathrm{L}$ in soft (alkalinity and hardness $=49 \mathrm{mg} / \mathrm{L}$ as $\mathrm{CaCO}_{3}$ ) laboratory water and $35 \mu \mathrm{g} / \mathrm{L}$ in river water (alkalinity $=68 \mathrm{mg} / \mathrm{L}$ as $\mathrm{CaCO}_{3}$, hardness $=81 \mathrm{mg} / \mathrm{L}$ as $\mathrm{CaCO}_{3}$ ), and Karen et al. [36] reported a 48-h LC50 of $0.84 \mu \mathrm{g} / \mathrm{L}$ (hardness $=100 \mathrm{mg} / \mathrm{L}$ as $\mathrm{CaCO}_{3}$ ). These data suggest that oxidation of the AgNP to ionic Ag at surface sites may play a role in observed toxicity. However, where the Ag ion forms (e.g., inside organism vs bulk medium) remains to be determined. Decreased toxicity observed in the tests with food may be explained by observations made by Glover and Wood [37] and Bianchini et al. [18] in D. magna, in which organic material may either alter availability of ionic Ag or stimulate active sodium uptake by $\mathrm{Na}^{+}, \mathrm{K}^{+}$-ATPase.

The differences in toxicity observed among the various nanoparticle suspensions are probably attributable to particle size. The particle size to which the organisms are exposed is partially a function of the degree of aggregation. The TEM images (Fig. 3) suggest that, even after filtration, the SA particles tend to aggregate more. Larger particles/aggregates decrease the surface area to volume ratio (relative to identical volumes of smaller particles) and thus decrease the surface area available to release $\mathrm{Ag}$ ion via oxidation reactions. Smaller particles will also be less prone to spatial hindrances when entering an organism. With the laboratory-synthesized particles, incomplete reactions may result in the presence of some residual Ag ion in the suspension. The images in Figure 3 and the filtration recoveries suggest, however, that most of the Ag present is particulate. Methods to differentiate between $\mathrm{Ag}$ ion and bulk Ag such as 1-kDa filters, dialysis, and microcapillary action were not used in the current study. Use of such methods would provide a more accurate characterization of Ag state (ion vs bulk) and thus greater insight on the exposure mechanism.

The results presented here suggest that, at minimum, AgNPs should be treated as Ag ions with respect to toxicity to D. magna neonates. Alternative methods (e.g., gene expression/ecotoxicogenomics) should be explored and may provide additional information regarding the toxicity of nanoparticles. Assessment of the ecotoxicity of nanoparticles presents challenges because of the burdensome nature of accounting for concentrations and transformations of nanoparticles in even simple media. Future research will focus on characterization and toxicity of AgNPs in increasingly complex matrixes.

\section{SUPPLEMENTAL DATA}

\section{Table S1.}

Figures S1-S7. (11.5 MB DOC)

Acknowledgement-Any opinions expressed in the current study are those of the authors and do not necessarily reflect the official positions and policies of the U.S. EPA. Any mention of products or trade names does not constitute recommendation for use by the U.S. EPA. Materials Research Collaborative Access Team operations are supported by the Department of Energy and the Materials Research Collaborative Access Team member institutions. The authors greatly appreciate the analytical support from the University of Cincinnati and Purdue University. The authors also thank Todd P. Luxton, Kirk G. Scheckel, Mark E. Smith, Sri Panguluri, and Christina BennetStamper for their insights and expertise. Christian Ritz, University of
Copenhagen, Denmark, provided valuable advice on dose-response statistical analyses.

\section{REFERENCES}

1. Lovern SB, Strickler JR, Klaper R. 2007. Behavioral and physiological changes in Daphnia magna when exposed to nanoparticle suspensions (titanium dioxide, nano-C-60, and $\mathrm{C}(60) \mathrm{HxC}(70) \mathrm{Hx}$ ). Environ $\mathrm{Sci}$ Technol 41:4465-4470.

2. Oberdorster E. 2004. Manufactured nanomaterials (fullerenes, C60) induce oxidative stress in the brain of juvinile largemouth bass. Environ Health Perspect 112:1058-1062.

3. Zhu S, Oberdorster E, Haasch ML. 2006. Toxicity of an engineered nanoparticle (fullerene, $\mathrm{C}_{60}$ ) in two aquatic species, Daphnia and fathead minnow. Mar Environ Res 62 Supplement 1:S5-S9.

4. Cheng J, Flahaut E, Cheng SH. 2007. Effect of carbon nanotubes on developing zebrafish (Danio rerio) embryos. Environ Toxicol Chem 26:708-716.

5. Smith CJ, Shaw BJ, Handy RD. 2007. Toxicity of single walled carbon nanotubes to rainbow trout, (Oncorhynchus mykiss): Respiratory toxicity, organ pathologies, and other physiological effects. Aquat Toxicol 82:94-109.

6. Zhu Y, Zhao Q, Li Y, Cai X, Li W. 2006. The interaction and toxicity of multi-walled carbon nanotubes with Stylonychia mytilus. J Nanosci Nanotechnol 6:1357-1364.

7. Adams LK, Lyon DY, Alvarez PJ. 2006. Comparative eco-toxicity of nanoscale $\mathrm{TiO}_{2}, \mathrm{SiO}_{2}$, and $\mathrm{ZnO}$ water suspensions. Water Res 40:35273532 .

8. Adams LK, Lyon DY, McIntosh A, Alvarez PJ. 2006. Comparative toxicity of nano-scale $\mathrm{TiO}_{2}, \mathrm{SiO}_{2}$ and $\mathrm{ZnO}$ water suspensions. Water $\mathrm{Sci}$ Technol 54:327-334.

9. Hund-Rinke K, Simon M. 2006. Ecotoxic effect of photocatalytic active nanoparticles $\left(\mathrm{TiO}_{2}\right)$ on algae and daphnids. Environ Sci Pollut Res Int $13: 225-232$

10. Davies JC. 2008. Nanotechnology oversight: An agenda for the new administration. The project on emerging nanotechnologies. Woodrow Wilson International Center for Scholars, Washington, DC.

11. Morones JR, Elechiguerra JL, Camacho A, Holt K, Kouri JB, Ramirez JT, Yacaman MJ. 2005. The bactericidal effect of silver nanoparticles. Nanotechnology 16:2346-2353.

12. Soni I, Salopek-Bondi B. 2004. Silver nanoparticles as antimicrobial agen: A case study on $E$. coli as a model for gram-negative bacteria. $J$ Colloid Interface Sci 275:1770-1782.

13. Luoma SN, Hogstrand C, Bell RA, Bielmyer GK, Galvez F, LeBlanc GA, Lee BG, Purcell TW, Santore RC, Santschi PH, Shaw JR. 2002. Biological Processes. In Andren AW, Bober TW, eds, Silver in the Environment: Transport, Fate, and Effects. SETAC, Pensacola, FL, USA, pp 65-91.

14. Jain P, Pradeep T. 2005. Potential of silver nanoparticle-coated polyurethane foam as an antibacterial water filter. Biotechnol Bioeng 90:59-63.

15. Sambhy V, MacBride MM, Peterson BR, Sen A. 2006. Silver bromide nanoparticle/polymer composites: dual action tunable antimicrobial materials. J Am Chem Soc 128:9798-9808.

16. Lee HY, Park HK, Lee YM, Kim K, Park SB. 2007. A practical procedure for producing silver nanocoated fabric and its antibacterial evaluation for biomedical applications. Chem Commun 28:2959-2961.

17. Wen C, Ishikawa K, Kishima M, Yamada K. 2000. Effects of silver particles on the photovoltaic properties of dye-sensitized $\mathrm{TiO}_{2}$ thin films. Sol Energy Mater Sol Cells 61:339-351.

18. Bianchini A, Wood CM. 2003. Mechanism of acute silver toxicity in Daphnia magna. Environ Toxicol Chem 22:1361-1367.

19. Wood CM, Playle RC, Hogstrand C. 1999. Physiology and modeling of mechanisms of silver uptake and toxicity in fish. Environ Toxicol Chem 18:71-83.

20. Elechiguerra JL, Burt JL, Morones JR, Camacho-Bragado A, Gao X, Lara HH, Yacaman MJ. 2005. Interaction of silver nanoparticles with HIV-1. J Nanobiotechnol 3:6.

21. Lee D, Cohen RE, Rubner MF. 2005. Antibacterial properties of Ag nanoparticle loaded multilayers and formation of magnetically directed antibacterial microparticles. Langmuir 21:9651-9659.

22. Navarro E, Piccapietra F, Wagner B, Marconi F, Kaegi R, Odzak N, Sigg L, Behra R. 2008. Toxicity of silver nanoparticles to Chlamydomonas reinhardtii. Environ Sci Technol 42:8959-8964.

23. Kramer JR, Benoit G, Bowles KC, DiToro DM, Herrin RT, LutherII GW, Manolopoulos H, Robillard KA, Shafer MM, Shaw JR. 2002. Environmental Chemistry of Silver. In Andren AW, Bober TW, eds, Silver in the Environment: Transport, Fate, and Effects. SETAC, Pensacola, FL, USA, pp 1-25. 
24. Choi O, Clevenger TE, Deng B, Surampalli RYL, Ross J, Hu Z. 2009. Role of sulfide and ligand strength in controlling nanosilver toxicity. Water Res 43:1879-1886.

25. Weber CI, ed. 1993. Methods for measuring the acute toxicity of effluents and receiving waters to freshwater and marine organisms, 4th ed. EPA 600/4-90/027F. U. S. Environmental Protection Agency, Washington, DC.

26. Pillai ZS, Kamat PV. 2004. What factors control the size and shape of silver nanoparticles in the citrate ion reduction method. J Phys Chem B 108:945-951.

27. United States Environmental Protection Agency. 1997. Method 3051: Microwave assisted acid dissolution of sediments, sludges, soils, and oils. In Test Methods for Evaluating Solid Waste, Physical/Chemical Methods, 2nd ed. Publication 955-001- 00000-1. U.S. Government Printing Office, Washington, DC

28. Ritz C, Streibig JC. 2005. Bioassay analysis using R. J Stat Softw 12:122.

29. R Development Core Team. 2009. R: A language and environment for statistical computing. R Foundation for Statistical Computing, Vienna, Austria.

30. Finney DJ. 1971. Probit Analysis, 3rd ed. Cambridge University, Cambridge, UK.
31. Collett D. 2003. Modeling Binary Data 2nd ed. Chapman and Hall/CRC, Boca Raton, FL, USA.

32. Ravel B, Newville M. 2005. Athena, Artemis, Hephaestus: Data analysis for X-ray absorption spectroscopy using IFEFFIT. J Synchotron Radiat 12:537-541.

33. International Organization for Standardization. 1996. Particle size analysis-photon correlation spectroscopy. ISO 13321: Geneva, Switzerland.

34. Elnabarawy MT, Welter AN, Robideau RR. 1986. Relative sensitivities of three daphnid species to selected organic and inorganic chemicals Environ Toxicol Chem 5:393-398.

35. Erickson RJ, Brooke LT, Kahl MD, VandeVenter F, Harting S, Markee TP, Spehar RL. 1998. Effects of laboratory test conditions on the toxicity of silver to aquatic organisms. Environ Toxicol Chem 17:572-578.

36. Karen DJ, Ownby DR, Forsythe BL, Bills TP, LaPoint TW, Cobb GB Klaine SJ. 1999. Influence of water quality on silver toxicity to rainbow trout (Oncorhynchus mykiss), fathead minnows (Pimephales promelas), and water fleas (Daphnia magna). Environ Toxicol Chem 18:63-70.

37. Glover CN, Wood CM. 2004. Physiological interactions of silver and humic substances in Daphnia magna: effects on reproduction and silver accumulation following an acute silver challenge. Comp Biochem Physiol C Toxicol Pharmacol 139:273-280. 